\title{
The Influence of Intro-extrovert Personality Types on Learned Helplessness in Programming Learning Using Training Kit
}

\author{
Semin Kim ${ }^{1, *}$, Kangsoo You ${ }^{2}$ \\ ${ }^{1}$ Department of Computer Education, Jeonju National University of Education, Republic of Korea \\ ${ }^{2}$ Department of Library and Information Science, Jeonju University, Republic of Korea
}

Copyright $\subseteq 2019$ by authors, all rights reserved. Authors agree that this article remains permanently open access under the terms of the Creative Commons Attribution License 4.0 International License

\begin{abstract}
Due to the Fourth Industrial Revolution, the software field has rapidly emerged as a major core field for the future. In particular, industrial specialized high schools are making efforts to cultivate people of talent in the software field under the policies of the Korean government. However, it has been a long-time concern within the educational fields that there are many learners who give up easily or display a lethargic attitude due to the various characteristics of a programming language. To improve this, students who took a class in programming subjects at an industrial specialized high school were studied. Each class section was divided into class groups that took a course that either utilized a programming training kit or did not. The groups were all classified, analyzed, and divided into two groups according to the results of their pre-tests. The results of this study indicate that quick identification of the learner's characteristics and application of teaching-learning activities is important. Additionally, building the environment needed for learning to have a positive impact on the learners' interests, learning motivation, and academic achievement is also important.
\end{abstract}

Keywords Personality Types, Training Kit, Programming Learning, Learned Helplessness, Software Education

\section{Introduction}

Recently, Korea's educational curriculum is being revised and reorganized to promote software education. Specialized high schools require graduates to get jobs at industrial sites, and these industrial specialized schools are also undergoing many changes. The schools have, until recently, been relatively weak in software education and programming learning compared to other subject areas.
However, in this, the 4th Industrial Era, the importance of the software subject area has begun to increase. Therefore, each department within industrial specialized high schools has begun to emphasize a convergence with the software subject area [1].

However, until recent years, teachers who could teach programming were not hired properly, and this often caused problems such as a lack of expertise and poor educational content. [2]

Also, the most difficult aspect about programming learning is that it is a subject of high concern but students may experience less interest in learning as well as poor academic achievement due to errors or difficult content. This may result in giving up on the learning entirely. There is also the danger, if they don't understand well, of copying and pasting the programming results of an honor student and just writing down the same thing.

Another difficulty in programming learning is that the content and academic achievement of the learning is likely to be determined by whether or not the school has the proper equipment. In other words, if students use learning aids, such as training kits or Arduino kits, while learning programming languages, they can improve the learning interest, participation, and active attitudes of students in comparison to traditional programming learning methods. This thereby increases student achievement in learning by allowing them to display imagination and creativity [3].

However, if schools do not have the proper equipment nor materials, there will be less learning motivation for students to learn programming, because the visible effects of this are static, which means that the learning interest and participation of students will be difficult to increase and can negatively affect further academic achievement. If these factors end in repeated poor learning, lethargy may become familiar result. This in turn may affect the student's learning of the next lesson or the learning of other subjects. 
Additionally, programming learning is a more liberal course of speech and action than general education. That is, students can use the Internet to search for and apply better algorithms, and when they are given a group challenge, they can discuss it with their peers to better solve the problem [4].

The purpose of this study is to investigate the relationship between the use of training kits in schools, and how introverted and extroverted personality types relate to learned helplessness [22].

\section{Related Research}

\subsection{Research for Programming Learning}

Recently, industrial specialized high schools have been trying to cope with changes in the demand of industrial sites for increased human resources. Also, the Ministry of Education of the Republic of Korea has demanded high employment rates in these areas [5], [6]. Therefore, industrial specialized high schools are pressing for education that meets the needs of these industries sites. Also, the importance of programming learning has been emphasized much in recent years and many studies have been conducted on various related topics [4],[23].

One of the reasons learners find the programming subject matter difficult is that, although they believe they have done a good job in learning, there are many potential errors. Because of this, they find it difficult to get interested in programming learning and do not learn it well. They also often give up on it or lose interest in learning it altogether. In the end, students often fall into lethargy each time they learn programming. There is a high probability that experiences such as these will be repeated and result in learned helplessness [24], [1]. As a way for programming learners to prevent this phenomenon of learned helplessness, they should be trained to improve computational thinking by systematically specifying ideas from the very basic stages of programming learning. For example, students may use the workbook to draw flow charts, which can help them identify what is difficult and where errors are likely to occur. In particular, industrial specialized high schools mostly use programming to input typed commands, and it is highly likely that simple typing errors will occur due to difficult grammar rules and Romanized characters, which are unfamiliar to Koreans. Teachers can predict this difficulty in academic achievement regarding programming learning, so that they can tailor the learning to the needs of their students by identifying these characteristics. This can help increase the learners' interest and academic achievement in programming learning [7], [8].

\subsection{Training Kits}

Recently, the decline in the ability of students to learn programming languages has made it difficult for them to learn programming in the educational fields. Therefore, various training kits are expected to contribute a lot to the educational fields as they motivate students toward programming learning and require creative engineering education programs [2], [9], [10].

In this study, training kits were grouped into three types. These include productized training kits, teacher-manufactured training kits, and training kits that are inexpensively constructed with open source hardware such as Arduino and Raspberry Pi controllers.

Productized training kits include 8 16-bit processors, such as Atmel's AVR processor and the ARM series of processors, or also open source hardware such as Arduino, Nucleo and Raspberry Pi. In addition, with these kits, it is possible to train with various motor and sensor components for actual robot control. Many industrial specialized high schools purchase and utilize such training kits, as shown in Fig. 1 [11].

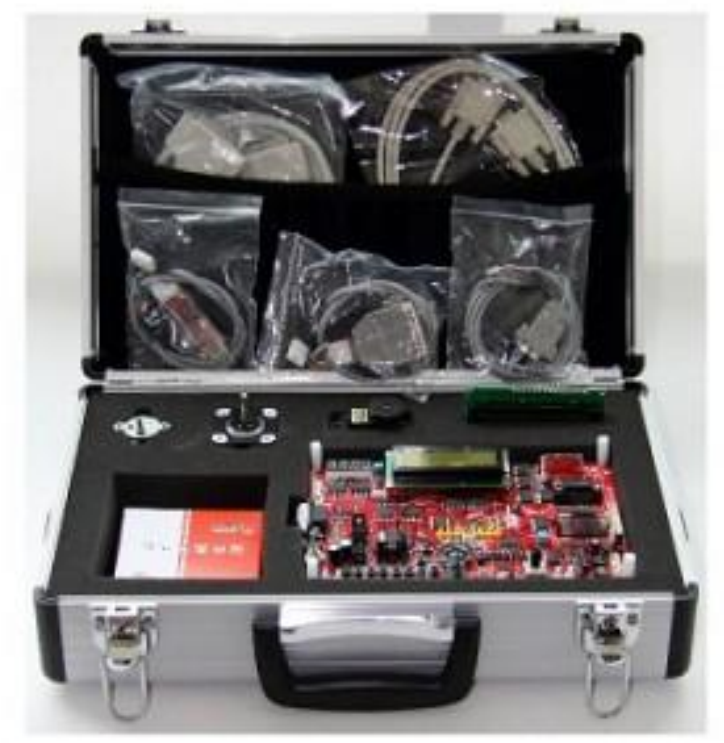

Figure 1. Training Kit for learning the AVR Processor

There are also cases where teachers have developed training kits themselves.

In a study that implemented micro-robots for the purpose of programming learning in the Java language, the NanoVM Java Virtual Machine was mounted into an Atmega8 AVR processor, and various peripheral devices and infrared sensors were attached to it to perform micro mice, lint racers, and mobile robot functions, as shown in Fig. 2.

In this study, the training kit, which is currently available as a mobile robot, has limitations that a variety of application robots cannot produce [10],[25]. There is also a high demand for teachers specialized in the curriculum.

Open source hardware, such as Arduino or Raspberry Pi, has been used more recently in organizing training kits that 
including motors and sensors, as shown in Fig. 3 [12]. Their advantage is that there are many resources available such as Internet sites and YouTube, and the price of these training kits can be much cheaper than the productized training kit shown in Fig. 1. The disadvantage is that there is a high possibility that parts will be lost.

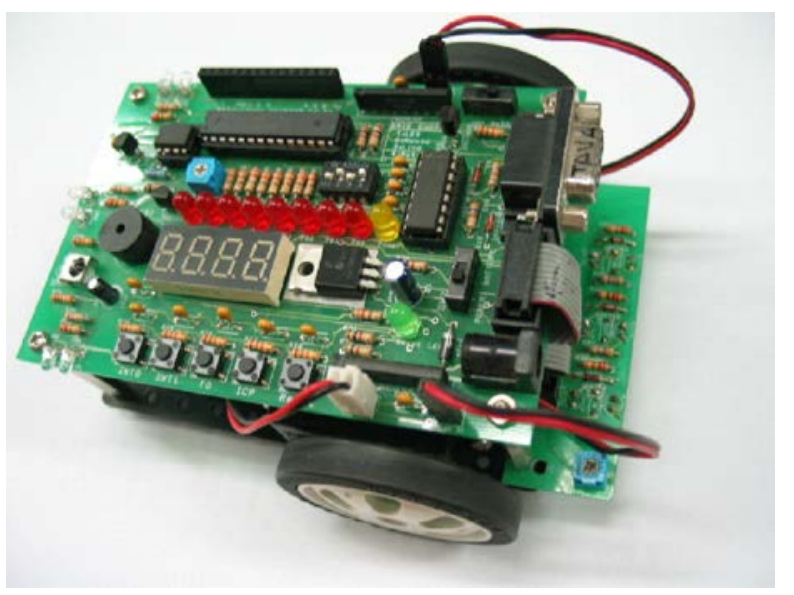

Figure 2. Java Micro Robot

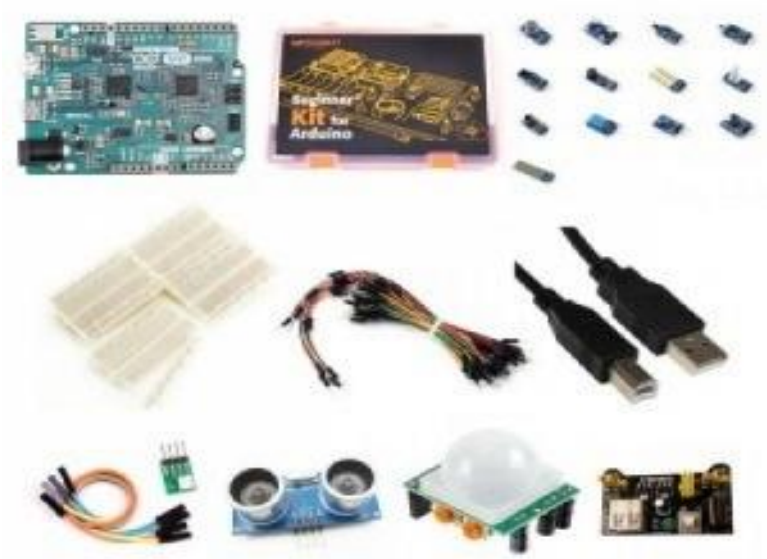

\section{Perfect Starter Kit}

Figure 3. Arduino Training Kit

\subsection{Utilization of Personality Type for Learning}

Personality types are classified as introverted and extroverted, depending on the direction in which they emit their energy. Generally, related research suggests that people with extroverted personality types have higher levels of overall happiness or satisfaction. The reason for this is that people with extroverted personality types often display more positive responses with emotional expressions in different situations than those with introverted personality types [13]-[15]. Based on this theory, many studies have been conducted considering personality types in learning.

In a study of web-based problem-oriented learning, grouped by personality type, it was found that learners with extroverted personality types had a higher level of interaction than introverted personality types. In other words, learners with extroverted personality types have a high frequency of discussion and communication at the social level [16].

Additional studies of personality types in programming learning have also been considered. After classifying learners into introverted personality types and extroverted personality types, the effects of programming learning motivation on self-directed learning was analyzed. The results of the study indicated that extroverted personality type learners displayed better results in their attitudes toward learning in general, and self-directed learning in particular, than introverted personality type learners at the beginning of the semester. But the differences between the two personality types could be reduced and improved upon with appropriate teacher guidance [4].

\subsection{Learned Helplessness}

Learning motivation is important in the introductory phase of learning in order to improve academic achievement. Several studies have shown that there is a positive correlation between learning motivation and academic achievement [17], [18]. However, it can be difficult to motivate learners in the introductory phase of learning.

The process of experiencing difficulties in the course of learning is bound to occur someday. However, if a student fails to overcome difficulties and gives up, or loses interest in learning, he or she will become lethargic.

If this situation is repeated enough, this lethargic state can become a learned, and is referred to as "learned helplessness". The theory of learned helplessness was first published by Seligman in 1972. He argued, "If an organism loses control of its environment, it learns to give up trying to control it as a result." [19].

Learned helplessness is distinguished from habitudinal helplessness [20],[26]. Habitudinal helplessness is a condition in which a learner is innately helpless. But learned helplessness occurs when a subject becomes accustomed to the helplessness of experiencing a certain situation that cannot be controlled, over and over again [21],[27][39]. Learners may experience helplessness resulting from minor mistakes in programming learning, or experience helplessness due to difficulty in learning content. Throughout this paper, the terms 'learning lethargy' and 'learned helplessness' are used interchangeably [28] [30] [31].

\section{Research Method}

\subsection{Objects and Limitation of Research}

The targets of this study were sophomore students attending the programming department of ' $\mathrm{A}$ ' Industrial 
Specialized High School in Jeollabuk-do, Republic of Korea. They had a shared experience in the $\mathrm{C}$ language in their freshman year.

This course was taught to them for one year from March to December 2018. The school had some classes that used training kits and some classes that did not. Each class section consisted of 15 students in six class groups, with the exception of a special technical class. There were 70 boys and 16 girls. This situation did not have an equal distribution of boys and girls.

Therefore, the limitations of this study are that it is not possible to study the difference in learned helplessness depending on gender.

\subsection{Research Process}

This study focused on the use of training kits among programming classes and on introverted and extroverted personality types. These considerations were applied to the design model where the students took pre-tests and post-tests on training kits and learning lethargy. An online survey was used as a method of surveying the students. The class was organized in this way according to the study before March.

The pre-test period was held for two weeks from March 2nd to March 15th. During this pre-test period, learning lethargy was checked. In addition, personality type tests were conducted to identify the personality types of the subjects. Based on the results from this section, the entire group of learners was classified as having either introverted or extroverted personality types. This study is not intended to be biased nor discriminate against students in light of their classification as either intro- or extroverted personality types. The purpose of this study is to investigate the ordinary everyday characteristics of the learners. Learners may also try to behave differently after learning their personality types beforehand. This situation does not suit the purpose of the study. Therefore, learners were informed that they would be notified about the results of the personality type test after all learning, and post-tests, had been completed.

After the pre-tests, programming learning was conducted as usual in the first and second semesters. The post-test period was from December 18th to December 31st,
2018 for two weeks. Post-tests only tracked learned helplessness. After the post-test, each learner was notified of the results of the original personality type test that had been conducted with the pre-tests. The SPSS 20.0 and AMOS 20 statistical packages were used for statistical verification of the research problems established based on the research results. The research model is shown in Fig. 1, and the experiments design is shown in Table 1 Table 4.

\subsection{Test Tools for Research}

There were two test tools used in this study.

First, an MBTI (Myers-Briggs Type Indicator) personality test was conducted to distinguish between introverted and extroverted personality types. Among the various results of the MBTI test, only introverted and extroverted personality types were separated and applied separately. The Cronbach alpha coefficient for this test tool is very good with all items being .91 or .92. Among them, the "E-I" (extroverted-introverted) item, which distinguishes between the two personality types, is .91 and is also very good.

Second, the learned helplessness diagnostic scale developed by K. M. Shin was used to identify learning lethargy. The scale consists of 45 questions for seven factors and includes a Likert 5-point scale. The seven factors on the test include (1) lack of self-confidence, (2) depression and negative perception, (3) passive attitude, (4) lack of control, (5) lack of continuity, (6) lack of desire to show off, and (7) lack of responsibility. The Cronbach alpha coefficient for this test tool is .77, which is relatively good.

\subsection{Programming Learning Syllabus}

In this study, there were some classes with training kits and some classes without training kits. A class that conducted a course with a training kit would be taught to control each part of the training kit using the $\mathrm{C}$ language. The training kit used in this study is shown in Fig. 4. Subjects without training kits were taught in Java only. Each class consisted of 17 weeks per semester. Table 1 Table 4. 
Table 1. Classes without Training Kits (First Semester)

\begin{tabular}{|c|c|c|}
\hline Weeks & Large Units & Small Units \\
\hline 1 & Orientation & $\begin{array}{l}\text { What is the Java programming language? } \\
\text { The concept of programming } \\
\text { programming language's development environment }\end{array}$ \\
\hline 2 & Java is? & $\begin{array}{l}\text { The features of the Java programming language } \\
\text { JVM (Java Virtual Machine) }\end{array}$ \\
\hline 3 & Variable & $\begin{array}{l}\text { Variables and constants } \\
\text { Data types \& Constants and literals } \\
\text { Input and Output }\end{array}$ \\
\hline 4 & Number system & $\begin{array}{l}\text { Decimal and binary } \\
\text { Bit and byte } \\
\text { Octal and hexadecimal }\end{array}$ \\
\hline 5 & Number system & $\begin{array}{l}\text { Number system: transformation of integers and real digits } \\
\text { Binary expression of negative digits }\end{array}$ \\
\hline 6 & Data types & Boolean, Character, Float/Double and Integer types \\
\hline 7 & \multicolumn{2}{|l|}{ Midterm examination } \\
\hline 8 & \multicolumn{2}{|c|}{ First performance assessment } \\
\hline 9 & Type Transformation & $\begin{array}{l}\text { What is type transformation? } \\
\text { Transformation between integers, real digits, integers-real digits } \\
\text { Automatic Transformation }\end{array}$ \\
\hline 10 & Operators & $\begin{array}{l}\text { The types of operators } \\
\text { Operator priority and associative principle } \\
\text { Unary, Arithmetic, Comparison, Logical, Etc. operator }\end{array}$ \\
\hline 11 & Conditional Structure & $\begin{array}{l}\text { If } \\
\text { If-else } \\
\text { If-else if } \\
\text { Repeated if } \\
\text { Switch-case }\end{array}$ \\
\hline 12 & Repetitive Structure & $\begin{array}{l}\text { For } \\
\text { While } \\
\text { Do-while } \\
\text { Break } \\
\text { Continue } \\
\end{array}$ \\
\hline 13 & Array & $\begin{array}{l}\text { Declaring and creating an Array } \\
\text { Length and index of Array } \\
\text { Initializing an Array } \\
\text { String Array }\end{array}$ \\
\hline 14 & Multi-dimensional Array & $\begin{array}{l}\text { Declaration and indexes of a two-dimensional Array } \\
\text { Initializing a two-dimensional Array } \\
\text { Adjustable Array } \\
\text { The use of multi-dimensional Arrays }\end{array}$ \\
\hline 15 & \multicolumn{2}{|c|}{ Second performance assessment } \\
\hline 16 & \multicolumn{2}{|c|}{ Finishing up for the first semester } \\
\hline 17 & \multicolumn{2}{|l|}{ Final examination } \\
\hline
\end{tabular}


Table 2. Classes without Training Kits (Second Semester)

\begin{tabular}{|c|c|c|}
\hline Weeks & Large Units & Small Units \\
\hline 1 & Initialization of variables & $\begin{array}{l}\text { Explicit initialization } \\
\text { Initialization block } \\
\text { Member variable }\end{array}$ \\
\hline 2 & Object-oriented language & The features of object-oriented languages \\
\hline 3 & Object-oriented language & $\begin{array}{l}\text { Overloading } \\
\text { Generator }\end{array}$ \\
\hline 4 & Object-oriented language & $\begin{array}{l}\text { Inheritance and Overloading } \\
\text { Packages and Imports } \\
\text { Controllers }\end{array}$ \\
\hline 5 & Object-oriented language & $\begin{array}{l}\text { Polymorphism } \\
\text { Abstract class } \\
\text { Interface and Inner class }\end{array}$ \\
\hline 6 & Exception handling & $\begin{array}{l}\text { Program Errors } \\
\text { Exception handling (try-catch), generation and Exception methods } \\
\text { Finally block }\end{array}$ \\
\hline 7 & Midterm examination & \\
\hline 8 & First performance assessm & \\
\hline 9 & Packages and Classes & $\begin{array}{l}\text { Java.lang package } \\
\text { Java.util package } \\
\text { Java.math package }\end{array}$ \\
\hline 10 & $\begin{array}{l}\text { Date and time } \\
\text { Formalization } \\
\end{array}$ & $\begin{array}{l}\text { Date and time } \\
\text { Formalization class }\end{array}$ \\
\hline 11 & $\begin{array}{l}\text { Collection } \\
\text { Frameworks }\end{array}$ & Overall content of collection and frameworks \\
\hline 12 & $\begin{array}{l}\text { Genesis } \\
\text { Enumeration types } \\
\text { Annotation }\end{array}$ & $\begin{array}{l}\text { Genesis } \\
\text { Enumeration types } \\
\text { Annotation }\end{array}$ \\
\hline 13 & Threading & Overall content of Threading \\
\hline 14 & $\begin{array}{l}\text { Input/ Output } \\
\text { Networking } \\
\end{array}$ & $\begin{array}{l}\text { Input/ Output } \\
\text { Networking }\end{array}$ \\
\hline 15 & \multicolumn{2}{|c|}{ Second performance assessment } \\
\hline 16 & \multicolumn{2}{|c|}{ Finishing up for the second semester } \\
\hline 17 & \multicolumn{2}{|l|}{ Final examination } \\
\hline
\end{tabular}

Table 3. Classes with Training Kits (First Semester)

\begin{tabular}{|l|l|l|}
\hline Weeks & Large Units & Small Units \\
\hline 1 & Orientation & $\begin{array}{l}\text { The construction of devices } \\
\text { The concept of programming } \\
\text { The construction of a development environment }\end{array}$ \\
\hline 2 & Main Board & $\begin{array}{l}\text { What is Main Board } \\
\text { Port inputs and outputs on the Main Board }\end{array}$ \\
\hline 3 & Actuators Module & What is a LED Module? \\
\hline 4 & Actuators Module & What is a RGB LED Module? \\
\hline 5 & Actuators Module & What is a Buzzer Module? \\
\hline 6 & Actuators Module & What is a Dot Matrix Module? \\
\hline 7 & Midterm examination & \multicolumn{2}{|l|}{} \\
\hline 8 & First performance assessment & What is a Text LCD Module? \\
\hline 9 & Actuators Module & What is a DC Motor? \\
\hline 10 & Actuators Module & What is a Servo Motor? \\
\hline 11 & Actuators Module & What is a Step Motor? \\
\hline 12 & Actuators Module & What is a temperature and humidity sensor? \\
\hline 13 & Sensor Module & What is an ultrasonic sensor? \\
\hline 14 & Sensor Module & \\
\hline 15 & Second performance assessment & \\
\hline 16 & Finishing up for the first semester \\
\hline 17 & Final examination & \\
\hline
\end{tabular}


Table 4. Classes with Training Kits (Second Semester)

\begin{tabular}{|c|c|c|}
\hline Weeks & Large Units & Small Units \\
\hline 1 & Sensor Module & What is a light sensor? \\
\hline 2 & Sensor Module & What is a PSD sensor? \\
\hline 3 & Sensor Module & What is a PIR sensor? \\
\hline 4 & Sensor Module & What is a potentiometer? \\
\hline 5 & Sensor Module & What is a sound sensor? \\
\hline 6 & Sensor Module & What is an infrared light reflex sensor? \\
\hline 7 & \multicolumn{2}{|l|}{ Midterm examination } \\
\hline 8 & \multicolumn{2}{|l|}{ First performance assessment } \\
\hline 9 & Sensor Module & What is a gas sensor? \\
\hline 10 & Sensor Module & What is a fire flame detection sensor? \\
\hline 11 & Sensor Module & What is a gyro sensor? \\
\hline 12 & Sensor Module \& Actuators Module & Interworking of LEDs and Sensors \\
\hline 13 & Sensor Module \& Actuators Module & Interworking of motors and sensors \\
\hline 14 & Sensor Module \& Actuators Module & Interworking of the Text LCD to Sensors \\
\hline 15 & \multicolumn{2}{|l|}{ Second performance assessment } \\
\hline 16 & \multicolumn{2}{|l|}{ Finishing up for the second semester } \\
\hline 17 & \multicolumn{2}{|l|}{ Final examination } \\
\hline
\end{tabular}

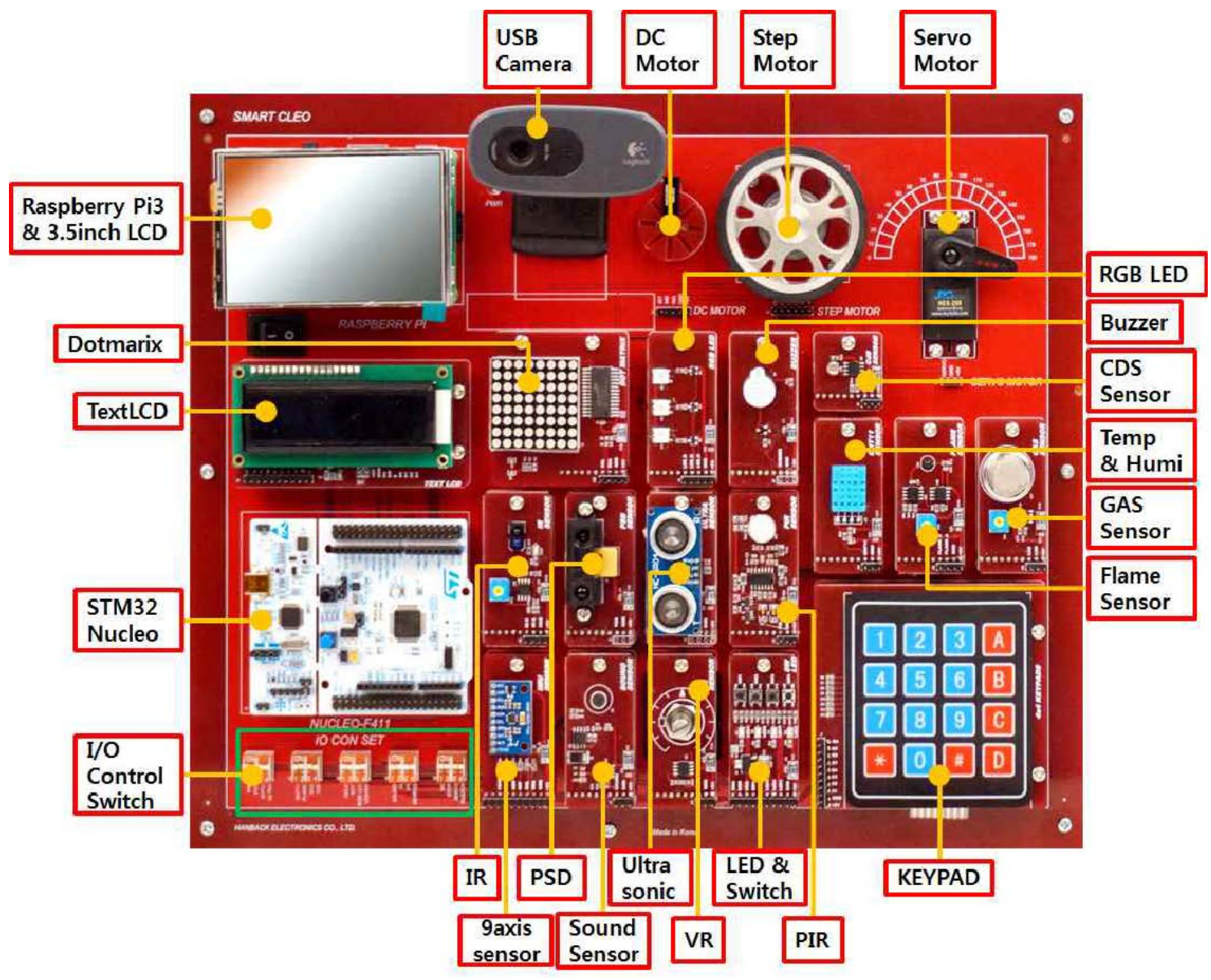

Figure 4. Training Kit Used in this Study 


\section{Research Results and Analysis}

\subsection{The Demographic Characteristics of Learners}

The group of male students consisted of 36 people with extroverted personality types and 34 people with introverted personality types. The group of female students consisted of 13 people with extroverted personality types and 3 people with introverted personality types.

Due to the nature of industrial specialized high schools, the number of male students far exceeded the number of female students, so research considering gender could not be done. However, since there were a total of 37 introverted personality types and 49 extroverted personality types, it was possible to study the learning lethargy of students according to personality type.

The study subjects were researched with pre-tests and demographically identified as shown in Fig. 5.

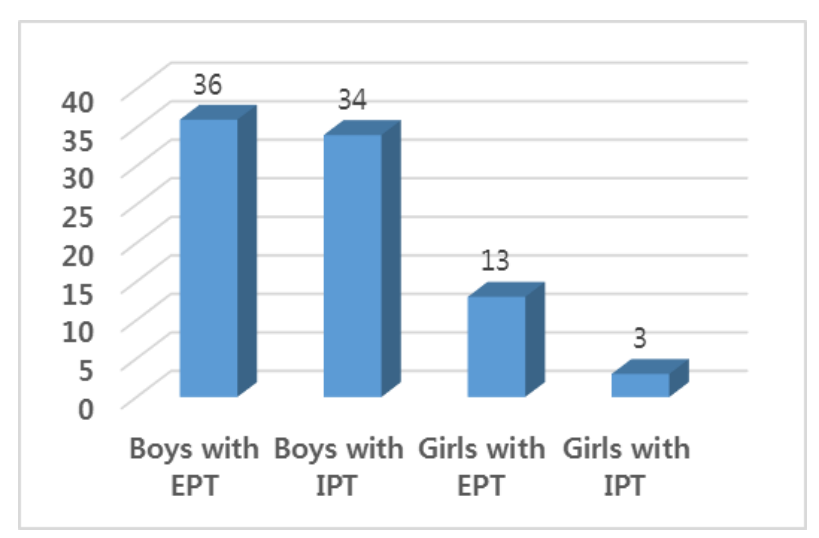

EPT indicates Extroverted Personality Types IPT indicates Introverted Personality Types

Figure 5. Demographics of this study

\subsection{Test of Learned Helplessness}

In this section, the results of pre-tests and post-tests of learned helplessness are analysed in connection with the introverted and extroverted personality type groups.

Table 5 and Fig. 6 show the results of the pre-tests of learned helplessness in the two groups.

The average of the extroverted personality type group is 3.18 , and the standard deviation is .301. The average of the introverted personality type group is 3.10 , and the standard deviation is .162. The $t$-Value is 1.509 and each significance probability (both sides, $\mathrm{p}>.05$ ) is .135 and .107. Thus, statistically, the results of the pre-tests of the two groups have no significant difference and therefore these can be considered to be the same group.

Table 6 and Fig. 7 show the results of post-tests of learned helplessness in the two groups.

The average of the extroverted personality type group is 3.56 , and the standard deviation is .468. The average of the introverted personality type group is 3.37 , and the standard deviation is .378. The t-Value is 2.134 and each significance probability (both sides, $\mathrm{p}>.05$ ) is .036 and .031. Thus, statistically, the results of the post-tests of the two groups have a significant difference. Therefore, between the two groups, it can be seen that the extroverted personality type group had improved upon their learning lethargy more than the introverted personality type group.

Table 5. Result of EPT's Pre-Test and IPT's Pre-Test

\begin{tabular}{|l|c|c|}
\hline & pre_EPT & pre_IPT \\
\hline $\mathbf{N}$ & 49 & 37 \\
\hline Avg. & 3.18 & 3.10 \\
\hline SD & .301 & .162 \\
\hline $\mathbf{T}$ & \multicolumn{2}{|c|}{1.509} \\
\hline $\begin{array}{l}\text { p } \\
\text { (p<0.05) }\end{array}$ & .135 & .107 \\
\hline Terms & $\begin{array}{l}\text { pre_EPT: pre-test for extroverted personality type } \\
\text { pre_IPT : pre-test for introverted personality type }\end{array}$ \\
\hline
\end{tabular}

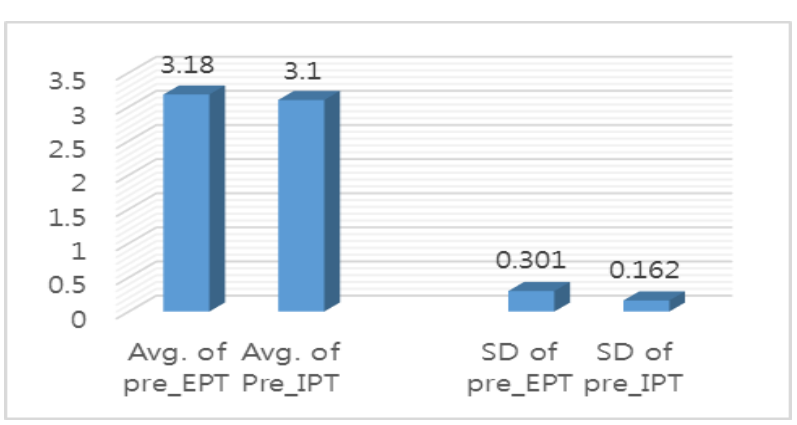

Figure 6. Graph of Avg. and SD (Table 5)

Table 6. Result of EPT Pre-Test and IPT Post-Test

\begin{tabular}{|l|c|c|}
\hline & post_EPT & post_IPT \\
\hline $\mathbf{N}$ & 49 & 37 \\
\hline Avg. & 3.56 & 3.37 \\
\hline SD & .468 & .378 \\
\hline $\mathbf{T}$ & \multicolumn{2}{|c|}{2.134} \\
\hline $\begin{array}{l}\mathbf{p} \\
(\mathbf{p}<\mathbf{0 . 0 5})\end{array}$ & .036 & .031 \\
\hline Terms & $\begin{array}{l}\text { post_EPT: post-test for extroverted personality type } \\
\text { post_IPT : post-test for introverted personality type }\end{array}$ \\
\hline
\end{tabular}

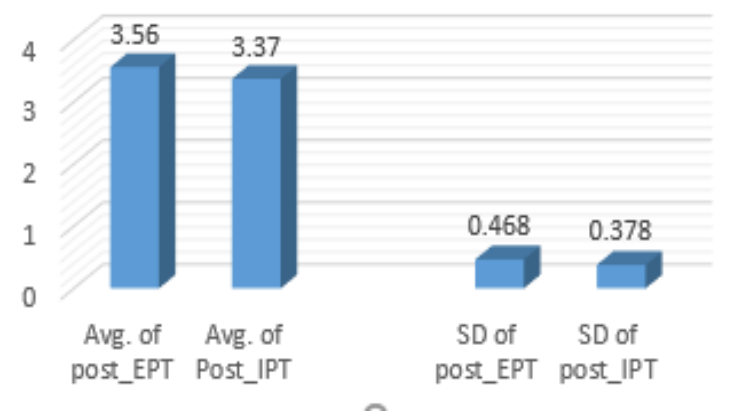

Figure 7. Graph of Avg. and SD (Table 6)

Table 7 and Fig. 8 shows pre-test and post-test results that compare and analyze statistics on learned helplessness for the introverted personality type group. 
The average of the introverted group's pre-test is 3.10, and the standard deviation is .162. The average of the introverted group's post-test is 3.36 , and the standard deviation is .378. The $\mathrm{t}$-Value is -3.773 and the significance probability (both sides, $\mathrm{p}>.05$ ) is .011 . The results show that the introverted personality type group did improve upon their learning lethargy as learning progressed.

Table 7. Result of IPT Pre-Test and IPT Post-Test

\begin{tabular}{|l|c|c|}
\hline & pre_IPT & post_IPT \\
\hline $\mathbf{N}$ & 37 & 37 \\
\hline Avg. & 3.10 & 3.36 \\
\hline SD & .162 & .378 \\
\hline $\mathbf{T}$ & \multicolumn{2}{|c|}{-3.773} \\
\hline $\begin{array}{l}\mathbf{p} \\
(\mathbf{p}<\mathbf{0 . 0 5})\end{array}$ & \multicolumn{2}{|c|}{.011} \\
\hline Terms & $\begin{array}{l}\text { pre_IPT: pre-test for introverted personality type } \\
\text { post_IPT : post-test for introverted personality type }\end{array}$ \\
\hline
\end{tabular}

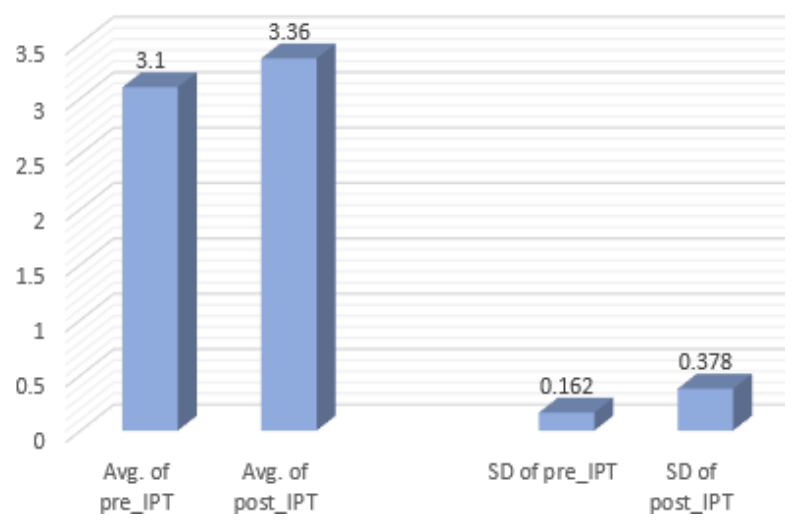

Figure 8. Graph of Avg. and SD (Table 7)

Table 8 and Fig. 9 show pre-test and post-test results that compare and analyze statistics on learned helplessness for the extroverted personality type group.

The average of the extroverted group's pre-test is 3.10, and the standard deviation is 3.18 , and the standard deviation is .301. The average of the extroverted group's post-test is 3.10 , and the standard deviation is 3.56 , and the standard deviation is .468. The t-Value is -4.689 and the significance probability (both sides, $\mathrm{p}>.05$ ) is .001 . The results show that the extroverted personality type group also improved upon their learning lethargy as learning progressed.

Table 8. Result of EPT Pre-Test and EPT Post-Test

\begin{tabular}{|l|c|c|}
\hline & pre_EPT & post_EPT \\
\hline $\mathbf{N}$ & 49 & 49 \\
\hline Avg. & 3.18 & 3.56 \\
\hline SD & .301 & .468 \\
\hline $\mathbf{T}$ & \multicolumn{2}{|c|}{-4.689} \\
\hline $\begin{array}{l}\mathbf{p} \\
(\mathbf{p}<\mathbf{0 . 0 5 )}\end{array}$ & \multicolumn{2}{|c|}{.001} \\
\hline Terms & $\begin{array}{l}\text { pre_EPT: pre-test for extroverted personality type } \\
\text { post_EPT : post-test for extroverted personality type }\end{array}$ \\
\hline
\end{tabular}

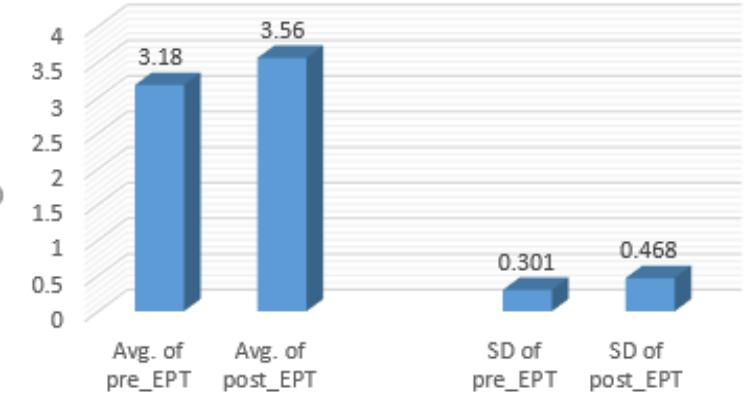

Figure 9. Graph of Avg. and SD (Table 8)

\subsection{Tests of Training Kit vs. Non-Training Kit Learners}

In this section, the results of pre-tests and post-tests of learned helplessness are analyzed in connection with the classes using Java programming and no training kits, and classes of programming learning with training kits.

Table 9 and Fig. 10 show the results of the pre-tests comparing learning lethargy between the classes using or not using the training kits.

The average of classes using the training kits is 3.13 and the standard deviation is .158 . The average of classes not using the training kit is 3.16 and the standard deviation is .323. The $\mathrm{t}$-Value is -.051 and the significance probability ( $p>05)$ is .229 . Thus, the results of tests of the two groups did not show a statistically significant difference, so they were considered to be the same group when the experiment was first started.

Table 9. Result of TKo Pre-Test and TKx Pre-Test

\begin{tabular}{|l|c|c|}
\hline & pre_TKo & pre_TKx \\
\hline $\mathbf{N}$ & 43 & 43 \\
\hline Avg. & 3.13 & 3.16 \\
\hline SD & .158 & .323 \\
\hline $\mathbf{T}$ & \multicolumn{2}{|c|}{-.051} \\
\hline $\begin{array}{l}\mid 2 \\
\mathbf{p}<\mathbf{0 . 0 5})\end{array}$ & \multicolumn{2}{|c|}{.229} \\
\hline Terms & $\begin{array}{l}\text { pre_TKo: pre-test for classes with training kits } \\
\text { pre_TKx: pre-test for classes without training kits }\end{array}$ \\
\hline
\end{tabular}

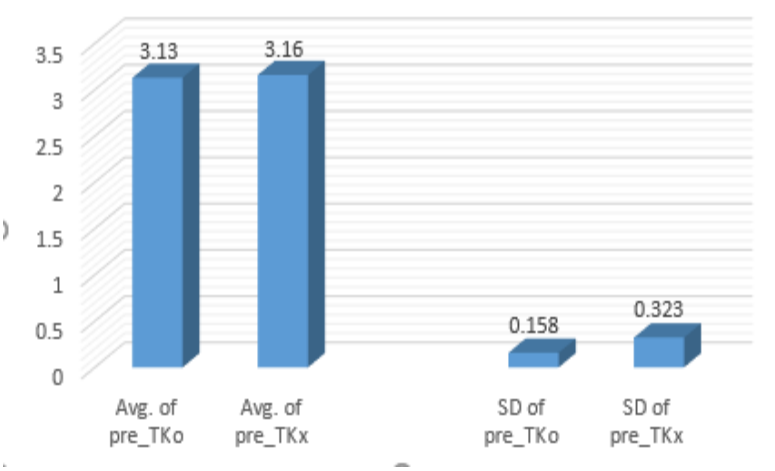

Figure 10. Graph of Avg. and SD (Table 9)

Table 10 and Fig. 11 show the results of the post-tests 
comparing learning lethargy between the classes using or not using the training kits.

The average of classes using the training kits is 3.30 and the standard deviation is .363. The average of classes not using the training kit is 3.13 and the standard deviation is .162. The $\mathrm{t}$-Value is 2.885 and the significance probability ( $>>05)$ is .005. Thus, statistically, the results of the post-tests of the two groups show a significant difference.

Table 10. Result of TKo Post-Test and TKx Post-Test

\begin{tabular}{|l|c|c|}
\hline & post_TKo & post_TKx \\
\hline $\mathbf{N}$ & 43 & 43 \\
\hline Avg. & 3.30 & 3.13 \\
\hline SD & .363 & .163 \\
\hline $\mathbf{T}$ & \multicolumn{2}{|c|}{2.885} \\
\hline $\begin{array}{l}\mathbf{p} \\
(\mathbf{p}<\mathbf{0 . 0 5 )}\end{array}$ & \multicolumn{2}{|c|}{.005} \\
\hline Terms & $\begin{array}{l}\text { post_TKo: post-test for classes with training kits } \\
\text { post_TKx: post-test for classes without training kits }\end{array}$ \\
\hline
\end{tabular}

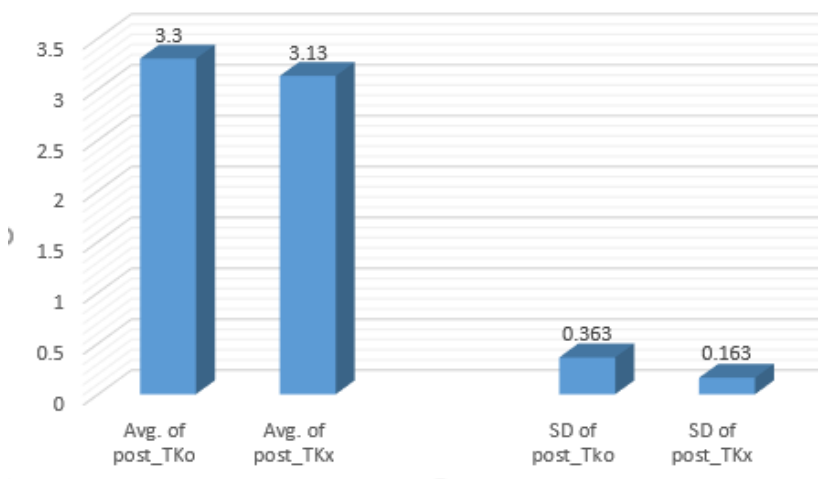

Figure11. Graph of Avg. and SD (Table 10)

Table 11 and Fig. 12 show pre-test and post-test results in classes that used the training kits.

The average pre-test of classes using the training kits is 3.13 and the standard deviation is .158. The average post-test of classes using the training kits is 3.30 , and the standard deviation is .363. The t-Value is -2.743 and the significance probability ( $>$ >05) is .007.The results showed that learning lethargy improved more in classes using the training kits than the classes not using the training kits. In addition, statistically, the results of the tests in the two groups showed significant differences.

Table 11. Result of TKo Pre-Test and TKo Post-Test

\begin{tabular}{|l|c|c|}
\hline & pre_TKo & post_TKo \\
\hline $\mathbf{N}$ & 43 & 43 \\
\hline Avg. & 3.13 & 3.30 \\
\hline SD & .158 & .363 \\
\hline T & \multicolumn{2}{|c|}{-2.743} \\
\hline $\begin{array}{l}\text { p } \\
(\mathbf{p}<\mathbf{0 . 0 5})\end{array}$ & \multicolumn{2}{|c|}{.007} \\
\hline Terms & $\begin{array}{l}\text { pre_TKo: pre-test for classes with training kits } \\
\text { post_TKo: post-test for classes with training kits }\end{array}$ \\
\hline
\end{tabular}

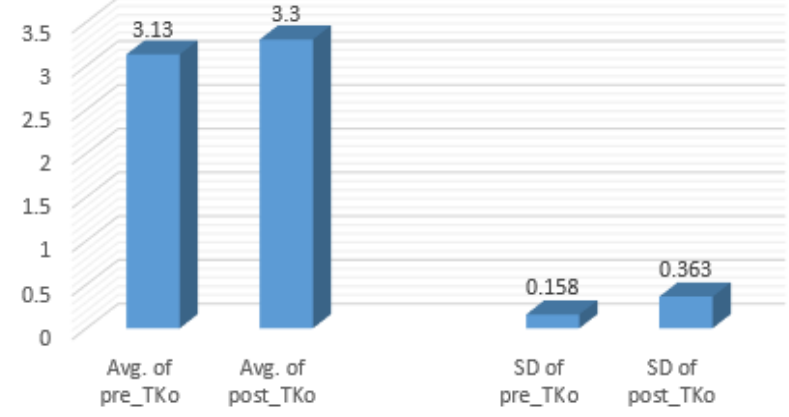

Figure 12. Graph of Avg. and SD (Table 11)

Table 12 and Fig. 13 show pre-test and post-test results in classes that did not use the training kits.

The average pre-test of classes not using training kits is 3.16 and the standard deviation is .323. The average post-test of classes not using the training kits is 3.13 , and the standard deviation is .162. The t-Value is .667 and the significance probability ( $\mathrm{p}>.05)$ is .165 . Thus, statistically, the results of the tests showed little significant differences and therefore indicate that students have not improved in learned helplessness.

Table 12. Result of TKx Pre-Test and TKx Post-Test

\begin{tabular}{|l|c|c|}
\hline & pre_TKx & post_TKx \\
\hline $\mathbf{N}$ & 43 & 43 \\
\hline Avg. & 3.16 & 3.13 \\
\hline SD & .323 & .162 \\
\hline $\mathbf{T}$ & \multicolumn{2}{|c|}{.667} \\
\hline $\mathbf{p}$ & \multicolumn{2}{|c|}{} \\
$\mathbf{( p < \mathbf { 0 . 0 5 } )}$ & \multicolumn{2}{|c|}{} \\
\hline Terms & $\begin{array}{l}\text { pre_TKx: pre-test for classes without training kits } \\
\text { post_TKx: post-test for classes without training kits }\end{array}$ \\
\hline
\end{tabular}

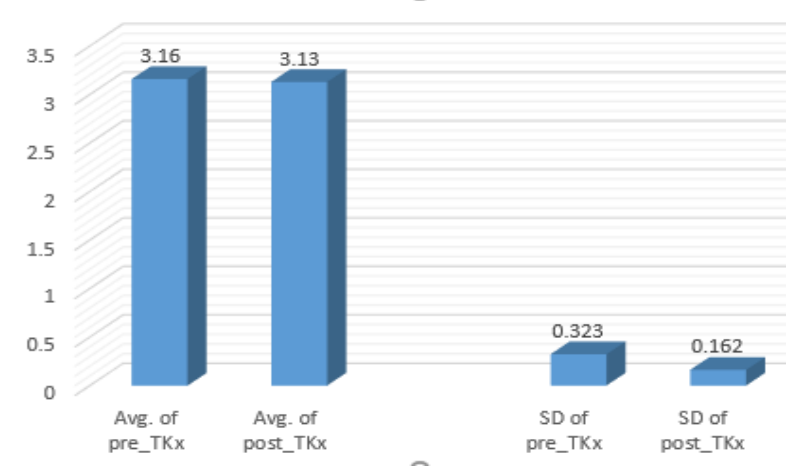

Figure13. Graph of Avg. and SD (Table 12)

\subsection{Discussion}

Based on the statistics demonstrated in this paper, learners with extroverted personality types were more likely to overcome learned helplessness than learners with introverted personality types. These results were evident throughout the study in that learners with extroverted personality types were heavily involved in active 
interaction and expression with other learners. It was also shown that classes using the training kit were better able to overcome learned helplessness than classes that were not using the training kit. Additionally, learners who used the training kits became interested in the device itself, and so were motivated to learn. The training kits enabled learners to dynamically express the results of programming, so they could quickly identify where errors occurred, and learn without giving up. This seems to have helped a lot in their learning.

\section{Conclusions and Suggestion}

The purpose of this study is to ensure that learners who take programming courses at industrial specialized high schools do not give up learning and fall into lethargy. In this study, learners at industrial specialize high schools were analyzed and observed for one year. Although it is difficult to secure many devices and materials at such school sites due to limited budgets, it will be necessary to pay attention to such school sites in order to effectively study these programming learners.

In addition, understanding the characteristics of the learners should encourage extroverts to continue to do well, and introverts should also be encouraged to more actively interact and express themselves with their peers.

Finally, future research plans aim to further refine the study by considering whether utilizing training kits and personality types have a significant impact on each other.

\section{REFERENCES}

[1] S. M. Kim and K. S. You, "The Effects of Introverted or Extroverted Personality Type on The Resilience of Java Programming Learning: Focused on Students at Technical-Specialized High School," Journal of The Korean Association of Information Education, vol. 22, no. 4, pp. 439-446, Aug. 2018.

[2] S. M. Kim and S. Y. Choi, “A Study of Programming Class using Raspberry Pi for Students of Industrial Specialized High School,” Journal of the Korea Institute of Information and Communication Engineering, vol. 21, no. 1, pp. 165-172, Jan. 2017.

[3] W. S. Moon, “The Effect of Convergent Programming Study Utilizing Scratch and Sensor Board on the Elementary School Students," Journal of The Korean Association of Information Education, vol. 21, no. 1, pp. 23-31, Feb. 2017.

[4] S. M. Kim and K. S. You, "The Effects of Introspective or Outgoing Personality Type on Programming Learning Motivation and Self-Directed Learning," Journal of the Korea Institute of Information and Communication Engineering, vol. 22, no. 8, pp. 1061 1067, Aug. 2018.

[5] W. S. Lee and T. W. Ahn, "A Study on the Improving Practical Education for Electronic Design Ability,” Journal of the Institute of Electronics and Information Engineers, vol. 51, no. 9, Sep. 2014.

[6] M. G. Lee, “A Study for the Effective Industry Field Training Management," Journal of The Institute of Electronics and Information Engineers, vol. 48, no. 3, pp. 33-39, Sep. 2011.

[7] W. S. Moon, "Analysis of Error Data Generated by Prospective Teachers in Programming Learning," Journal of The Korean Association of Information Education, vol. 22, no. 2, pp. 205-212, Apr. 2018.

[8] Y. M. Choi, “Analysis and Application of Misconception Flowchart for Programming Control Structure Concept Learning,” Journal of Korea Multimedia Society, vol. 20, no. 12, pp. 2000-2008, Dec. 2017.

[9] S. Y. Choi and S. M. Kim, "Effects of Physical Computing Education Using App Inventor and Arduino on Industrial High School Students' Creative and Integrative Thinking,” Journal of the Korean Association of Computer Education, vol. 19, no. 6, pp. 45-54, Nov. 2016.

[10] J. H. Baek, "The Design And Implementation of Robot Training Kit for Java Programming Learning," Journal of The Korea Society of Computer and Information, vol. 18, no. 10, pp. 97-107, Oct. 2013.

[11] Eleparts Co. LTD (2019). website. [Online]. Available: https://eleparts.co.kr/goods/view?no=1170236/

[12] Eleparts Co. LTD (2019). website. [Online]. Available: https://eleparts.co.kr/goods/view?no=4226843/

[13] E. M. Park and T. Y. Jung, "Differences in Happiness between Extroverts and Introverts: Happiness with Different Colors," Korean Journal of Social and Personality Psychology, vol. 29, no. 1, Feb. 2015.

[14] Cao, M. The Cultivation of Cultural Consciousness in English Writing Teaching in China from the Perspective of Linguistics. Humanities and Social Sciences Letters, 6(1), 1-9. 2018.

[15] Çelik, I., Çalik, F., Bayraktar, G., \& Bayram, M. The Investigation on Physical Education Teacher Candidate's Resilience, Tenacity and Motivation Levels. Journal of Education and e-Learning Research, 5(3), 174-178. 2018.

[16] Chidobi, R. U. Extent of Implementation of Nuc Regulation by Private Universities in Enugu State on Personnel Management. American Journal of Education and Learning, 2(1), 83-91. 2017.

[17] Çoban, O., \& Yildirim, M. The Comparison of High School Students' Level of Aggression Based on Demographic Features. Asian Journal of Education and Training, 4(4), 363-370. 2018.

[18] De, A. C., Kurian, S., Dinithi, M. K., Hareesh, N., \& Saira, P. Social Media for Higher Education: A Cross Sectional Study among Teachers in India and Sri Lanka. Humanities and Social Sciences Letters, 6(4), 180-188. 2018.

[19] Parnornmast C, Jermsittiparsert K, Sriyakul T. Empirical discourse analysis on correlations between exchange rate and exports. Social and Management Research Journal. 2013, Vol. 2; 10(2):39-51.

[20] Demirel, I. N., Teyfur, M., Çelik, I., Safali, S., \& Kaya, A. 
Perspectives of Preservice Teachers on the Statements Related to Preservice Teachers and Competence of Lecturers. Journal of Education and e-Learning Research, 5(3), 185-192. 2018.

[21] Dierker, L., Evia, J. R., Singer-Freeman, K., Woods, K., Zupkus, J., Arnholt, A., ... \& Rose, J. Project-Based Learning in Introductory Statistics: Comparing Course Experiences and Predicting Positive Outcomes for Students from Diverse Educational Settings. International Journal of Educational Technology and Learning, 3(2), 52-64. 2018.

[22] Haseeb M, Zandi G, Hartani NH, Pahi MH, Nadeem S. Environmental Analysis of the Effect of Population Growth Rate on Supply Chain Performance and Economic Growth of Indonesia. Ekoloji. 2019, Vol. 28(107):417-26.

[23] L. D. Smillie, A. J. Cooper, J. Wilt and W. Revelle, "Do Extraverts Get More Bang for the Buck? Refining the Affective-Reactivity Hypothesis of Extraversion,” Journal of Personality and Social Psychology, vol. 103, pp. 306-326, Aug. 2012.

[24] L. Helgoe, Introvert Power. Seoul, Korea: Heureum Books, 2009.

[25] J. H. Park and H. D. Song, "The Effect of Personality Grouping and Communication Types on Learners' Interaction in Web-Based Problem-Based Learning," The Journal of Korean Educational Forum, vol. 10, no. 3, pp. 41 62, Oct. 2011.

[26] H. C. Cho, "The Effects of Academic Motivation, Self-Determination, Goal Orientation, Self-Perception, Implicit Theory of Intelligence and Self-Regulated Learning Strategies on Learning Attitude, Behavior and Outcomes," The Korean Journal of Educational Psychology, vol. 25, no. 1, pp.33-60, Jan. 2011.

[27] Vallerand, R. J., \& O'Connor, B. P. “Construction et validation de I'Échelle de Motivation pour les Personnes Âgées (EMPA) [Construction and validation of the Elderly Motivation Scale]," International Journal of Psychology, vol. 26, no. 2, pp. 219-240. Apr. 1991

[28] Seligman M. E. P., "Positive Social Science," Journal of Positive Behavior Interventions, vol. 1 no. 3, pp. 181-182. Mar. 1999.

[29] J. H. Bae, “The Effects of Interpersonal Relationship, School Learning History, and Motivational Variables on Learned Helplessness,” Ph.D. dissertation, Kangwon National University, Chooncheon, Korea, Feb. 2008.

[30] Ahmed U, Zin ML, Majid AH. Impact of Intention and Technology Awareness on Transport Industry's E-service: Evidence from an Emerging Economy. 산경연구논집 (IJIDB). 2016, Vol. 30; 7(3):13-8.

[31] G. M. Yang, “A Study on Developing Learned Helplessness Reduction Program for Spiritual Growth: Case Study of Seoul West Parish,” Ph. D., dissertation, Sunmoon University, Asan, Korea, Feb. 2016. 